17 T These authors contributed equally to this work

*Corresponding author-malik.sundip@gmail.com University, Hisar-125004, India Agriculture \& Technology, Pantnagar-263145, India

\title{
Physical localization of 45S rDNA in Cymbopogon and the analysis of differential
} distribution of rDNA in homologous chromosomes of Cymbopogon winterianus

${ }^{1}$ Department of Molecular Biology and Genetic Engineering, College of Basic Sciences and Humanities, G. B. Pant University of Agriculture \& Technology, Pantnagar-263145, India

${ }^{2}$ Department of Molecular Biology, Biotechnology and Bioinformatics, CCS Haryana Agricultural

${ }^{3}$ Department of Genetics and Plant Breeding, College of Agriculture, G. B. Pant University of

${ }^{4}$ Department of Botany, Deva Nagri P.G. College, CCS University Meerut-245206, India

${ }^{5}$ Division of Genetics \& Plant Breeding, Sher-e-Kashmir University of Agricultural Sciences \& Technology of Kashmir (SKUAST-Kashmir), Srinagar-190025, (J\&K), India

\section{Abstract}

20 Cymbopogon, commonly known as lemon grass, is one of the most important aromatic grasses

21 having therapeutic and medicinal values. FISH signals on somatic chromosome spreads off 22 Cymbopogon species indicated the localization of $45 \mathrm{~S}$ rDNA on the terminal region of short arms 23 of a chromosome pair. A considerable interspecific variation in the intensity of $45 \mathrm{~S}$ rDNA 
24 hybridization signals was observed in the cultivars of Cymbopogon winterianus and Cymbopogon

25 flexuosus. Furthermore, in all the varieties of Cymbopogon winterianus namely Bio-13, Manjari

26 and Medini, a differential distribution of 45S rDNA was observed in a heterologous pair of

27 chromosome 1. The development of Cymbopogon winterianus var. Manjari through gamma

radiation may be responsible for breakage of fragile rDNA site from one of the chromosomes of

this heterologous chromosome pair. While, in other two varieties of Cymbopogon winterianus

(Bio-13 and Medini), this variability may be because of evolutionary speciation due to natural

cross among two species of Cymbopogon which was fixed through clonal propagation. However,

in both the situations these changes were fixed by vegetative method of propagation which is general mode of reproduction in the case of Cymbopogon winterianus.

\section{Introduction}

35 Cymbopogon, commonly known as lemon grass, is one of the most important aromatic grasses species display wide variation in morphological attributes and essential oil composition at inter and intraspecific levels [2]. The first cytological study in Indian Cymbopogon to ascertain the

42 chromosome number [3-4] indicated the different ploidy levels in these genera varying from diploid $(2 n=20)$ to tetraploid $(2 n=40)$ and hexaploid $(2 n=60)$. However, as per available reports in

44 literature, the cytogenetic studies in this genus have been limited to chromosome count and preliminary karyotype description of the cultivated species. The characterization of Cymbopogon 
47 some molecular markers such as RAPD and SSR [6]. Analysing the genome organization of plants

48 reveal evolutionary relationships of different genomes, which may also be useful for crop

49 improvement. The ribosomal RNA genes represent two highly conserved tandemly arrayed gene

50 families namely 45S rDNA and 5S rDNA which have been studied extensively in plant genomes.

51 Because of the numerous copies of these highly conserved families of repeated sequences, their

52 physical location on the chromosome can be easily visualized. The 45S rDNA sites in somatic

53 chromosomes are most extensively utilized and widely documented chromosomal regions in

54 eukaryotes through fluorescent in situ hybridization (FISH). The 45S rDNA family together with

55 the intergenic spacer (IGS) is present as tandem arrays within the nucleolus organizer regions

56 (NORs) of satellite chromosomes and also at other chromosomal sites where they may not be

57 associated with NOR [7-9]. Length polymorphism of these repeat units has been reported in a wide

58 range of plants and animals and are attributed to variation in number of sub-repeats that are found

59 in IGS. The length of IGS and the chromosomal location of 45S rDNA genes are often

60 characteristic of a species and were widely used to study the phylogenetic relationships of several

61 plant species [10-13]. In view of the limited cytological reports on Cymbopogon, molecular

62 cytogenetic studies for the identification of individual chromosomes are urgently needed in this

63 important crop. Therefore, the present investigation was conducted using 45S rDNA as a probe to

64 develop valuable FISH landmarks of somatic chromosomes of Cymbopogon which may be utilized

65 in subsequent molecular cytogenetic studies to generate physical maps of Cymbopogon species.

\section{Results}

\section{Karyotype analysis}

68 All the four varieties studied during the present investigation were observed as diploid with 69 chromosome number $(2 n=20)$. Variety Bio-13 belonging to $C$. winterianus is one of the supreme 
70 significantly commercialized variety of Java Citronella grass. This variety of C. winterianus

71 contain diploid chromosome complement as $2 n=20$ with basic chromosome number $x=10$ (Fig.

72 1a, 1c and 2a). Arm ratios for the chromosomes of this species ranged from 1.05 to 3.37 (Fig. 2a)

73 and the range of chromosome lengths lies between 1.3 to $3.12 \mu \mathrm{m}$. Bio-13 observed to have 3

74 chromosomes in the range of 2.0 to $3.0 \mu \mathrm{m}(3 \mathrm{C})$ and rest of the seven chromosomes in the range

75 of 1 to $2 \mu \mathrm{m}$ (7D). As per the arm ratios of different chromosomes of this variety, 3 chromosomes

76 were metacentric and 7 were sub-metacentric (Table 1).

77 Manjari (C. winterianus) also shows its somatic chromosome complement as $2 n=20$ (diploid) with

78 basic chromosome number $x=10$ (Fig. 1d). Arm ratios for the chromosomes of this species ranged

79 from 1.05 to $3.38 \mu \mathrm{m}$ and the range of chromosome lengths lies between 1.31 to $2.98 \mu \mathrm{m}$ (Fig. 2b)

80 which is almost equivalent to $C$. winterianus var. Bio-13. This variety is observed to have 2

81 chromosomes in the range of 2.0 to $3.0 \mu \mathrm{m}$ ( $2 \mathrm{C}$ chromosomes) and rest of the eight chromosomes

82 ranged in 1.0 to $2.0 \mu \mathrm{m}$ ( $8 \mathrm{D}$ chromosomes). As per the arm ratios (Table 1) of different

83 chromosomes of this variety, 3 chromosomes were metacentric and 7 were sub-metacentric.

84 Medini (C. winterinaus) is comparatively new variety than above two varieties of $C$. winterianus

85 which is also classified under Java Citronella grass with $2 n=20$ as its somatic chromosome

87 and the range of chromosome lengths lies between 1.70 to $3.10 \mu \mathrm{m}$ (Fig. 2c). The length of two

88 chromosome ranged between 2.0 to $3.0 \mu \mathrm{m}$ ( $2 \mathrm{C}$ chromosomes) and other eight chromosomes were

89 ranged in 1.0 to $2.0 \mu \mathrm{m}$ (8 D chromosomes). As per the arm ratios of different chromosomes of 90 this variety, 3 of them were characterized as metacentric whereas 7 of them were characterized as 91 sub-metacentric (Table 1). 
92 Krishna (C. flexuosus), also contains the somatic chromosome complement of $2 n=20$ (Fig. 1f).

93 The arm ratios of the chromosomes of this species ranged from 1.07 to 2.22 and the range of

94 chromosomes length lies between 1.48 to $2.30 \mu \mathrm{m}$ (Figure $2 \mathrm{~d}$ ). This showed that C. flexuosus var.

95 Krishna had slightly smaller chromosomes than $C$. winterianus. As per the arm ratios of different

96 chromosomes of this variety, 5 of the chromosomes were metacentric and other 5 were sub-

97 metacentric (Table 1).

\section{Localization of $45 S$ rDNA}

99 Bio-13 (C. winterianus) had shown strong hybridization signal of 45S rDNA at the terminal ends 100 of short arms of the longest heterologous pair of somatic chromosome complement. The

101

102

103

104

105

106

107

108

109

110

111

112

113

114

differential signal intensity of 45S rDNA was observed in different stages like metaphase (Fig. 1a and 1c) and interphase (Fig. 1b). The relative length of $45 \mathrm{~S}$ rDNA hybridization signal in one chromosome of the heterologous bivalent was $29.48 \%(0.92 \mu \mathrm{m})$ of the whole chromosome while the relative length of $45 \mathrm{~S}$ rDNA in another chromosome of this pair was $10.01 \%(0.28 \mu \mathrm{m})$. Surprisingly, the signal intensity on both the chromosomes of this heterologous chromosome pair is not equal which is indicating the differential copy number of rDNA in both chromosomes of this heterologous chromosome pair.

Manjari (C. winterianus) had also shown strong hybridization signals of 45S rDNA at the terminal ends of short arms of longest heterologous pair of its chromosome complement (Fig 1d). Similar to the Bio-13, the differential signal intensity of $45 \mathrm{~S}$ rDNA was observed in metaphase chromosomes of Manjari (Fig 1d). The relative length of 45S rDNA signal in one chromosome of the heterologous bivalent was $26.51 \%(0.79 \mu \mathrm{m})$, while the relative length of $45 \mathrm{~S}$ rDNA in other chromosome of this pair was recorded $11.59 \%(0.32 \mu \mathrm{m})$ which is indicating the differential copy number of rDNA in both chromosomes of this heterologous chromosome pair. 
115

116

117

118

119

120

121

122

123

124

125

126

\section{Discussion}

128 As reflected from the results, the arm ratios for the chromosome of $C$. winterianus ranged from

129

130

131

132

133

134

135

136

137

Medini (C. winterianus) had shown to have strong hybridization signals of $45 \mathrm{~S}$ rDNA at the terminal ends of short arms of longest heterologous pair of its chromosome complement (Fig 1e).

Similar to the Bio-13 and Manjari, this variety of $C$. winterianus also showed differential signal intensity of $45 \mathrm{~S}$ rDNA in metaphase chromosomes. The relative length of $45 \mathrm{~S}$ rDNA signal in one chromosome of the heterologous bivalent was $26.12 \%(0.81 \mu \mathrm{m})$ while the relative length of $45 \mathrm{~S}$ rDNA in other chromosome of this pair was recorded $11.72 \%(0.32 \mu \mathrm{m})$ which is indicating the differential copy number of rDNA in both chromosomes of this heterologous chromosome pair.

Krishna (C. flexuosus) had shown to have strong hybridization signals of 45S rDNA at the terminal ends of short arms of longest chromosome pair of its chromosome complement. However, in contrast to differential signal intensity of $45 \mathrm{~S}$ rDNA shown in all the three varieties of $C$. winterianus, this species had shown to have the 45S rDNA signals of similar intensity i.e., 32.60\% and $33.18 \%$ on both chromosomes of longest homologous chromosome pair (Fig 1f).

1.05 to 3.37 and the range of chromosomes length lies between 1.3 to $3.12 \mu \mathrm{m}$ (Fig. 2). These results are in almost accordance of previous karyomorphological observation [14] where he reported the average arm ratio 1.26 and the chromosomal length in the range of 1.3 to $3.15 \mu \mathrm{m}$ of the species $C$. winterianus Jowitt. As per the arm ratios of different chromosomes of all the genotypes of $C$. winterianus, 3 chromosomes are metacentric and 7 are sub-metacentric. These results are in contrast to the previous investigation [14] where $C$. winterianus was reported to have 8 sub-metacentric and 2 metacentric chromosomes. This difference may be due to small size of the chromosomes as sometimes it may be difficult to identify the centromeric position of the chromosomes. However, during the present investigation we have recorded the data on several 
138 cells and the data were based on average length and hence seems to be more authentic. The slight

139 variation observed in the karyotypes of $C$. winterianus may be due to phenomenon of differential

140 chromatin condensation in different chromosomes. Further, the lemon grass variety Krishna $(C$.

141 flexuosus) has also shown its somatic complement as $2 n=20$ with basic chromosome number $x=$

14210 (Fig. 1f and 2d) which is very common in many of the species of Cymbopogon. The average

143 chromosome arm ratios of C. flexuosus (1.95) are slightly varied from the arm ratio (1.53) of earlier

144 reports [14].

145 In the past few decades, the extensive study of many plant species for localization of 45S rDNA

146 genes have been done through FISH technique and it has been observed that, most of diploid plants

147 have two sites rDNA i.e., a single locus [15]. Even though, some diploids exist with numerous

148 sites of rDNA. The rDNA copy number changes rapidly and frequently, triggering relocation or

149 deletion of some loci over and above the reduction in copy number below the detection sensitivity

150 limit or mapping resolution [16-17]. For the justification of these differences some mechanisms

151 have been proposed by various workers, such as various chromosome rearrangements, unequal

152 crossing-over, gene transposition (gene mobility), and conversion [18-20]. There is certain proof

153 that rDNA sites may alter chromosomal position, lacking the contribution of translocations [19].

154 Some of other observations have led to the suggestion that rDNA tandem repeats are mobile, with

155 different molecular mechanisms believed to be intricated in this type of movement [21-22].

156 Signifying the transposition of the rDNA loci [23] triggered by En/Spm-like transposons

$157[17,21,24]$, this procedure might designate chromosomal re-patterning of rDNA, which appears to

158 be triggered through En/Spm-like transposons being accountable for drifting of rDNA to a new

159 location [17]. Examples for arithmetical changes in 45S rDNA sites were described for few

160 additional species, like in the colchicine-induced auto tetraploid Arabidopsis thaliana [25], 
161 signifying the $45 \mathrm{~S}$ rDNA-bearing chromosome reorganization, as an entity of intragenomic translocation, and in tetraploid Centaurea jacea [26] in which the deletion of one pair of 45S rDNA loci was observed. Unluckily, there was lack of concrete evidence about mechanism involved in rDNA loci variation, so further studies need to be done in order to find the reasons behind the variation in pattern of rDNA loci.

166 The observations recorded during the present investigation are slightly different as the 167 polymorphism has been observed within the same loci which exist at the short arms of two 168 chromosomes of a homologous pair which seems like a rare observation, 'as it is well known fact that in case of variation in rDNA present in two chromosomes of a homologous pair it will be equilibrated by subsequent round of crossing over and recombination in next generations. Krishna

171 is a variety of C. flexuosus which is developed from variety Pragati and Cauveri (C. flexuosus)

172 through phenotypic recurrent selection programme [27]. The crosses led to homogenization of 173 genes through recombination and crossing over hence there is no polymorphism in rDNA sites 174 (Fig. 1f and 2d) on both the homologous chromosomes and thus the intensity of rDNA 175 hybridization signals remain similar in both chromosomes. However, Bio-13 (C. winterianus) was 176 developed through mutation breeding. Manjari was developed by irradiation of the slips of variety 177 Manjusha with gamma rays and Medini was developed by clonal selection of some of the well 178 performing commercial varieties of $C$. winterianus. These facts prompted us to explore the 179 possibilities for differential distribution of $45 \mathrm{~S}$ rDNA in both chromosomes of a homologous 180 chromosome pair existed in the above-mentioned varieties of $C$. winterianus. Java citronella, i.e., C. winterianus flowers copiously in South India and at higher attitudes

182 in the hills of North Eastern India. However, due to irregularities in meiosis and chromosome 183 polyploidy, viable seeds are not formed and therefore, the species can be propagated only by 
184 vegetative means. As per perusal of different literature we come across the fact that

185 heterochromatin sites are fragile in nature and are prone to degeneration upon the exposure of

186 physical and chemical mutagens. Considering the importance of these species there are several

187 programmes running in different institutions to increase quantity and quality aspect. The

188 development of $C$. winterianus var. Manjari through gamma radiation may be responsible for

189 breakage of fragile rDNA site from the chromosome or this variability may be due to evolutionary

190 speciation due to natural cross among two different species of Cymbopogon which is fixed due to

191 clonal propagation (Fig. 3). However, in both the situations these changes were fixed by vegetative

192 method of propagation which is general mode of reproduction in the case of $C$. winterianus. Thus,

193 the varieties of $C$. winterianus never got chance to recover by chromosome homogenization. This

194 may be the reason why the change got fixed in cells of these varieties of $C$. winterianus. For the

195 variety Medini of $C$. winterianus which is developed through clonal selection from Manjari and

196 having the same background. The $C$. winterianus var. Bio-13 is developed by in vitro somaclonal

197 selection [28]. However, seed setting in C. flexuosus var. Krishna takes place in all regions of

198 India, and hence developed through cross pollination and recurrent selection. In addition to

199 vegetative propagation, it is also being propagated through seeds, hence there is equal opportunity

200 of chromosomal recovery in each generation.

\section{Material and Methods}

\section{Plant materials}

203 Four varieties of two Cymbopogon species namely C. winterianus (Medini, Manjari, Bio-13) and

204 C. flexuosus (Krishna) were collected from Central Institute of Medicinal and Aromatic Plants

205 (CIMAP), Research Centre, Pantnagar, Uttarakhand, India. The information concerning the details

206 of cultivars, chromosome number and percentage listed in Table 1. 


\section{Preparation of chromosome spreads}

208 The procedure of mitotic chromosome preparation was basically the same as published protocols 209 [29] with some modifications. The slips of these cultivars were covered with moist paper and kept 210 in a tray for root initiation in dark under room temperature for $68-72 \mathrm{hr}$. Lateral roots of about 1

$211 \mathrm{~cm}$ were pre-treated in $0.002 \mathrm{~mol} / \mathrm{L} 8$-hydroxyquinoline at room temperature for $2 \mathrm{~h}$, then fixed in

212 3:1 Carnoy's fixative solution for at least 1 day. To obtain the chromosome preparations, fixed 213 root tips were digested with enzyme mixtures, containing 4\% cellulose Onozuka R-10 214 (Merck,http://www.merck-chemicals.com) and $2.0 \quad \% \quad$ pectinase (Sigma-Aldrich, 215 http://www.sigmaaldrich.com) in $1 \mathrm{X}$ PBS buffer, pH 5.5, at $37^{\circ} \mathrm{C}$ for $50 \mathrm{~min}$. The enzyme solution 216 was replaced by deionized water and kept on ice for at least $8 \mathrm{~min}$. Following, the digested root

217 tips were fixed in 3:1 Carnoy's fixative. The slides were obtained using a "flame-dried" method, 218 according to the published protocol [30].

219 Probe preparation

220 Plasmid pTa71 with a size $9.0 \mathrm{~kb}$ from wheat [31] was used for 45S rDNA sites. rDNA was 221 labelled with Fluorescein-12-dUTP (ROCHE Diagnostics) using the nick translation method.

\section{Signal detection and analysis}

223 A $30 \mu 1$ of hybridization mixture contained $15 \mu 1$ of deionized formamide, $3 \mu 1$ of $20 \mathrm{X} \mathrm{SSC}, 6 \mu 1$ 224 of $50 \%$ dextran sulphate, $1 \mu \mathrm{l}$ of Salmon sperm DNA, $2 \mu 1$ of probe DNA and $3 \mu 1$ of dd $\mathrm{H}_{2} \mathrm{O}$ was 225 added to denatured slide and covered with plastic coverslip. The slides were then incubated at $37^{\circ}$

226 C in moist chamber overnight for hybridization of labelled probe with target DNA. After overnight 227 incubation, slides were washed three times in 2X SSC for $5 \mathrm{~min}, 50 \%$ formamide in $2 \mathrm{X}$ SSC for $22810 \mathrm{~min}$ and three times with $2 \mathrm{X} \mathrm{SSC}$ for $5 \mathrm{~min}$ each at $42^{\circ} \mathrm{C}$ in water bath. This was followed by 229 subsequent washing in $1 \mathrm{X}$ SSC for $5 \mathrm{~min}$ at RT. The slides were counterstained with propidium 
230 iodide and mounted with single drop of anti-fade mounting medium (Vectashield) and covered

231 with $22 \times 30 \mathrm{~mm}$ coverslips.

232 Photographs of cells were captured with well spread chromosomes by epifluorescence Zeiss

233 Axioimager MI microscope (Carl Zeiss, Germany). The mean length of each chromosome,

234 chromosome length, long arm, short arm and arm ratio of each chromosome and percentage of 45S

235 rDNA signals were obtained through measurements with MicroMeasure 3.3 software

236 (http://www.colostate.edu/Depts/Biology/MicroMeasure). The karyograms were developed using

237 above parameters obtained through MicroMeasure 3.3.

238 Acknowledgments

239 The author acknowledged the support of Central Institute of Medicinal and Aromatic Plants

240 (CIMAP), Research Centre, Pantnagar, Uttarakhand, India for providing the germplasm. The

241 research was performed at Molecular Cytogenetics Laboratory, Department of Molecular Biology

242 \& Genetic Engineering, College of Basic Sciences \& Humanities, G. B. Pant University of

243 Agriculture \& Technology, Pantnagar, Uttarakhand.

\section{References}

1. Shasany A K, Lal RK, Darokar MP, Patra NK, Garg A, Kumar S, Khanuja SPS. Phenotypic and RAPD diversity among Cymbopogon winterianus Jowitt accessions in relation to Cymbopogon nardus Rendle. Genetic Resources and Crop Evolution 2000; 47(5): 553-9. https://doi.org/10.1023/A:1008712604390.

2. Rao BL. Scope for development of new cultivars of Cymbopogon as a source of terpene chemicals. In: Handa SS, Kaul MK, editors. Supplement to cultivation and utilization of 
aromatic plants. National Institute of Science Communication, Dr. KS. Krishnan Marg, New Delhi, India; 1997.p. 71-83.

3. Babu CN. Chromosome numbers in Cymbopogon species. Current Science 1936; 4(10): 739 $-40$.

4. Bor NR. The genus Cymbopogon Spreng. In India Burma and Ceylon Part I. Journal of the Bombay Natural History Society 1953; 51: 890 - 916.

257 5. Sangwan NS, Yadav U, Sangwan RS. Molecular analysis of genetic diversity in elite Indian cultivars of essential oil trade types of aromatic grasses (Cymbopogon species). Plant Cell Reports 2001; 20(5): 437 - 44. https://doi.org/10.1007/s002990100324.

6. Kumar J, Verma V, Goyal A, Shahil AK, Sparoo R, Sangwan RS, Qazi GN. Genetic diversity analysis in Cymbopogon species using DNA markers. Plant Omics Journal 2009; 2(1): 20-9.

7. Mukai Y, Endo TR, Gill BS. Physical mapping of the $18 \mathrm{~S}-26 \mathrm{~S}$ rRNA multigene family in common wheat: identification of a new locus. Heredity 1991; 100(2):71-8 https://doi.org/10.1007/bf00418239.

8. Leitch IJ, Heslop-Harison, JS. Physical mapping of the $18 \mathrm{~S}-5.8 \mathrm{~S}-26 \mathrm{~S}$ rDNA genes in barley by in situ hybridization. Genome 1992; 35(6): 1013 - 18. https://doi.org/10.1139/g92- 155.

9. Pedersen C, Linde-Laursen I. Chromosome location of four minor rDNA loci and marker microsatellite sequence in barley. Chromosome 1994; 2(1): 65-71. https://doi.org/10.1007/bf01539456. and 18S-26S ribosomal RNA gene families in diploid species. Genome 1996; 39(6): 115058 https://doi.org/10.1139/g96-145. 
11. Raina SN, Mukai Y. Detection of a variable number of $18 \mathrm{~S}-5.8 \mathrm{~S}-26 \mathrm{~S}$ and $5 \mathrm{~S}$ ribosomal DNA loci by fluorescence in situ hybridization in diploid and tetraploid Arachis species. Genome 1999; 42(1): 52 - 59. https://doi.org/10.1139/g98-092.

12. Ansari HA, Ellison NW, Reader MS, Badaeva ED, Friebe B, Miller TE, Williams WM. Molecular Cytogenetic Organization of 5S and 18S-26S rDNA Loci in White Clover (Trifolium repens L.) and Related Species. Annals of Botany 1999; 83(3): 199 - 206 https://doi.org/10.1006/anbo.1998.0806.

13. Taketa S, Ando H, Takeda K, Bothmer VR. Physical locations of 5S and 18S-25S rDNA in Asian and American diploid Hordeum species with the $I$ genome. Heredity 2001; 86(5): 522 - 30 https://doi.org/10.1046/j.1365-2540.2001.00768.x.

14. Lavania UC. Karyomorphological observations in Cymbopogon Sprengel. Cytologia 1988; 53(3): 517-24. https://doi.org/10.1508/cytologia.53.517.

15. Mishima M, Ohmido N, Fukui K, Yahara T. Trends in site number change of rDNA loci during polyploid evolution in Sanguisorba (Rosaceae). Chromosoma 2002; 110(8): 550 -8. https://doi.org/10.1007/s00412-001-0175-z.

16. Jiang J, Gill BS. New 18S.26S ribosomal RNA gene loci: chromosomal landmarks for the evolution of polyploidy wheats. Chromosoma 1994; 103(3):179-185. https://doi.org/10.1007/s004120050022.

17. Raskina O, Belyayev, A. and Nevo, E. Activity of the En/Spm-like transposons in meiosis as a base for chromosome re-patterning in a small, isolated, peripheral population of Aegilops speltoides Tausch. Chromosome Research 2004; 12(2): 153-61.

18. Schubert I, Wobus U. In situ hybridization confirms jumping nucleolus organizing regions in Allium. Chromosoma 1985; 92(2): 143 - 48. https://doi.org/10.1007/bf00328466. 
19. Dubcovsky J, Dvorak J. Ribosomal RNA multigene loci: nomads of the Triticeae genomes.

297

298

299

300

301

302

303

304

305

306

307

308

309

310

311

312

313

314

315

316 Genetics 1995; 140(4): 1367-77.

20. Thomas HM, Harper JA, Morgan WG. Gross chromosome rearrangements are occurring in an accession of the grass Lolium rigidum. Chromosome Research 2001; 9 (7): 585 - 90 https://doi.org/10.1023/A:1012499303514.

21. Datson PM, Murray BG. Ribosomal DNA locus evolution in Nemesia: transposition rather than structural rearrangement as the key mechanism. Chromosome Research 2006; 14(8): 845 - 857. https://doi.org/10.1007/s10577-006-1092-z.

22. Pedrosa-Harand A, De Almeida CCS, Mosiolek M, Blair MW, Schweizer D, Guerra M. Extensive ribosomal DNA amplification during Andean common bean (Phaseolus vulgaris L.) evolution. Theoretical and Applied Genetics 2006; 112 (5): 924 -33. https://doi.org/10.1007/s00122-005-0196-8.

23. Frello S, Heslop-Harrison JS. Chromosomal variation in Crocus vernus Hill (Iridaceae) investigated by in situ hybridization of rDNA and a tandemly repeated sequence. Annals of Botany2000; 86(2): 317 - 22. https://doi.org/10.1006/anbo.2000.1189.

24. Raskina O, Belyayev A, Nevo E. Quantum speciation in Aegilops: Molecular cytogenetic evidence from rDNA cluster variability in natural populations. Proceedings of National Academy of Sciences of the USA 2004; 101(41): 14818 - 14823.

25. Weiss H, Maluszynska J. Chromosomal rearrangement in autotetraploid plants of Arabidopsis thaliana. Hereditas 2000; 133(3): 255 - 61. https://doi.org/10.1111/j.16015223.2000.00255.x. 
26. Dydak M, Kolano B, Nowak T, Siwinska D, Maluszynska J. Cytogenetic studies of three European species of Centaurea L. (Asteraceae). Hereditas 2009; 146 (4): 152 - 61. https://doi.org/10.1111/j.1601-5223.2009.02113.x.

27. Improved Clonal variety Krishna of lemongrass developed. CIMAP Newsletter 1997; 24: 23.

28. Patra NK, Kumar B. Improved Varieties and Genetic Research in Medicinal and Aromatic Plants (MAPs). In: Proceedings of Second National Interactive Meet (NIM) on Medicinal and Aromatic Plants, Lucknow, India 2005; 53-61.

29. Lou QF, He YH, Cheng CY, Zhang ZH, Li J, Huang, SW Chen JF. Integration of highresolution physical and genetic map reveals differential recombination frequency between chromosomes and the genome assembling quality in cucumber. Plos ONE 2013; 8(5): e62676. doi: 10.1371/journal.pone.0062676. PMID: 23671621.

30. Iovene M, Wielgus SM, Simon PW, Buell CR, Jiang JM. Chromatin structure and physical mapping of chromosome 6 of potato and comparative analysis with tomato. Genetics 2008; 180(3): 1307-17.

31. Gerlach WN, Bedbrook JR. Cloning and characterization of ribosomal RNA genes from wheat and barley. Nucleic Acids Res 1979; 7(7): 1869 - 85.https://doi.org/10.1093/nar/7.7.1869.

32. Lal RK, Sharma JR, Misra HO. Development of new variety Manjari of Citronella Java $(C$. winterianus). Journal of Medicinal and Aromatic Plant Science 1999; 21: 727 - 29.

33. High yielding varieties Jalpallavi, Manjari and Medini of Citronella Java (Cymbopogon winterianus), CIMAP Newsletter 1999; 26: 3 - 5. 
Table 1. Description of karyotyping in all the varieties.

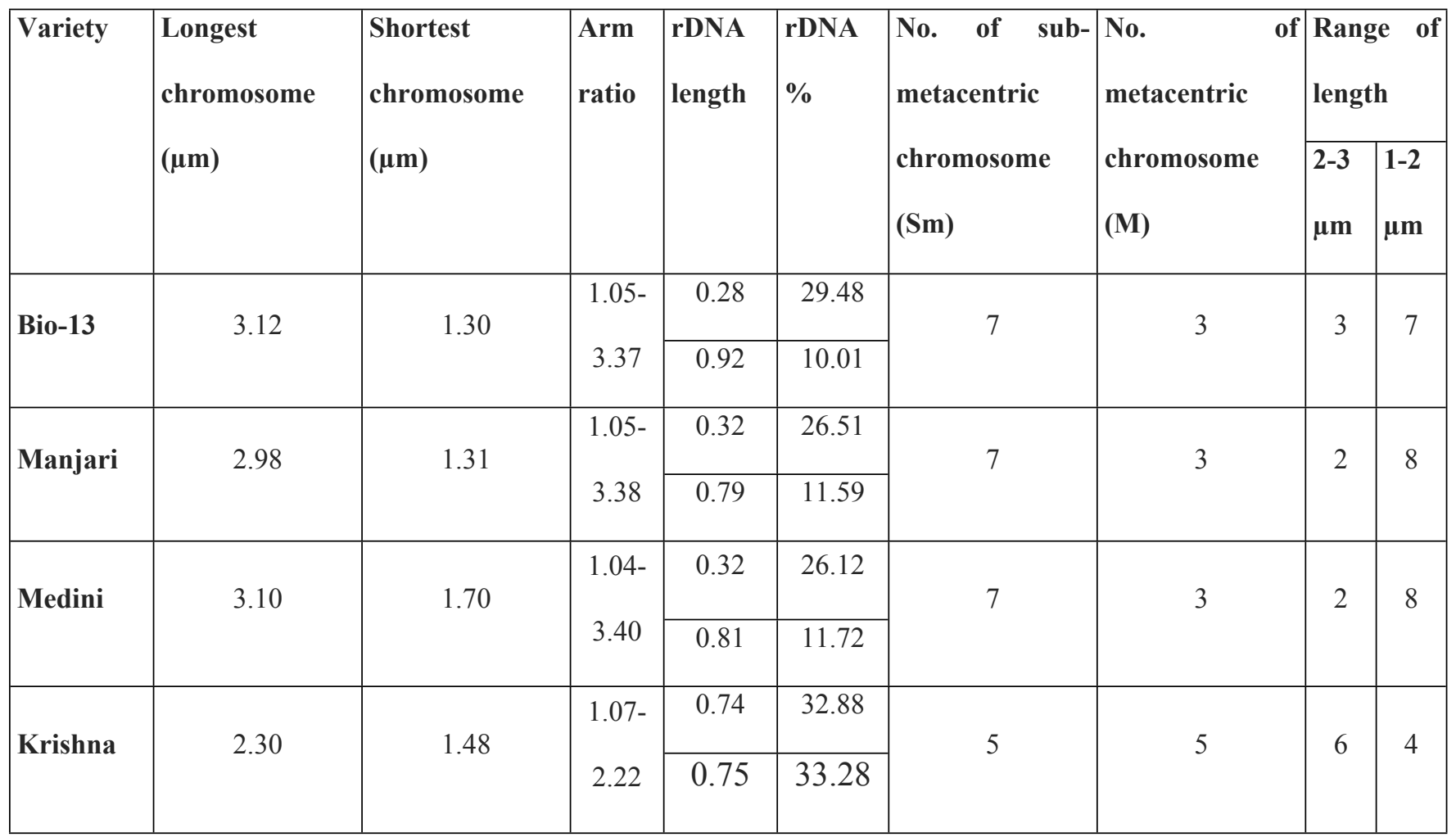

\begin{tabular}{|l|l|l|l|}
\hline \multirow{2}{*}{ Species } & Varieties & \multicolumn{1}{|c|}{$\begin{array}{c}\text { Chromosome } \\
\text { number }\end{array}$} & Parentage/Development \\
\hline \multirow{2}{*}{ C. flexuosus } & Krishna & 20 & Phenotypic recurrent selection $^{27}$ \\
\hline \multirow{2}{*}{ C. winterianus } & Manjari & 20 & Induced Mutagenesis $^{32}$ \\
\cline { 2 - 4 } & Medini & 20 & Clonal selection $^{33}$ \\
\cline { 2 - 4 } & Bio-13 & 20 & In vitro somaclonal selection \\
& & & \\
\hline
\end{tabular}


Figure 1. Mitotic cells of variety Bio-13, Medini, Manjari (C. winterianus) and Krishna ( $C$. $(2 n=20)$ showing differential hybridization signals of $45 \mathrm{~S}$ rDNA on a pair of somatic hybridization signals of 45S rDNA on a pair of somatic chromosomes.

Figure 2. Total length and arm ratio of chromosome. Schematic representation of chromosome of Krishna (C.flexuosus). 


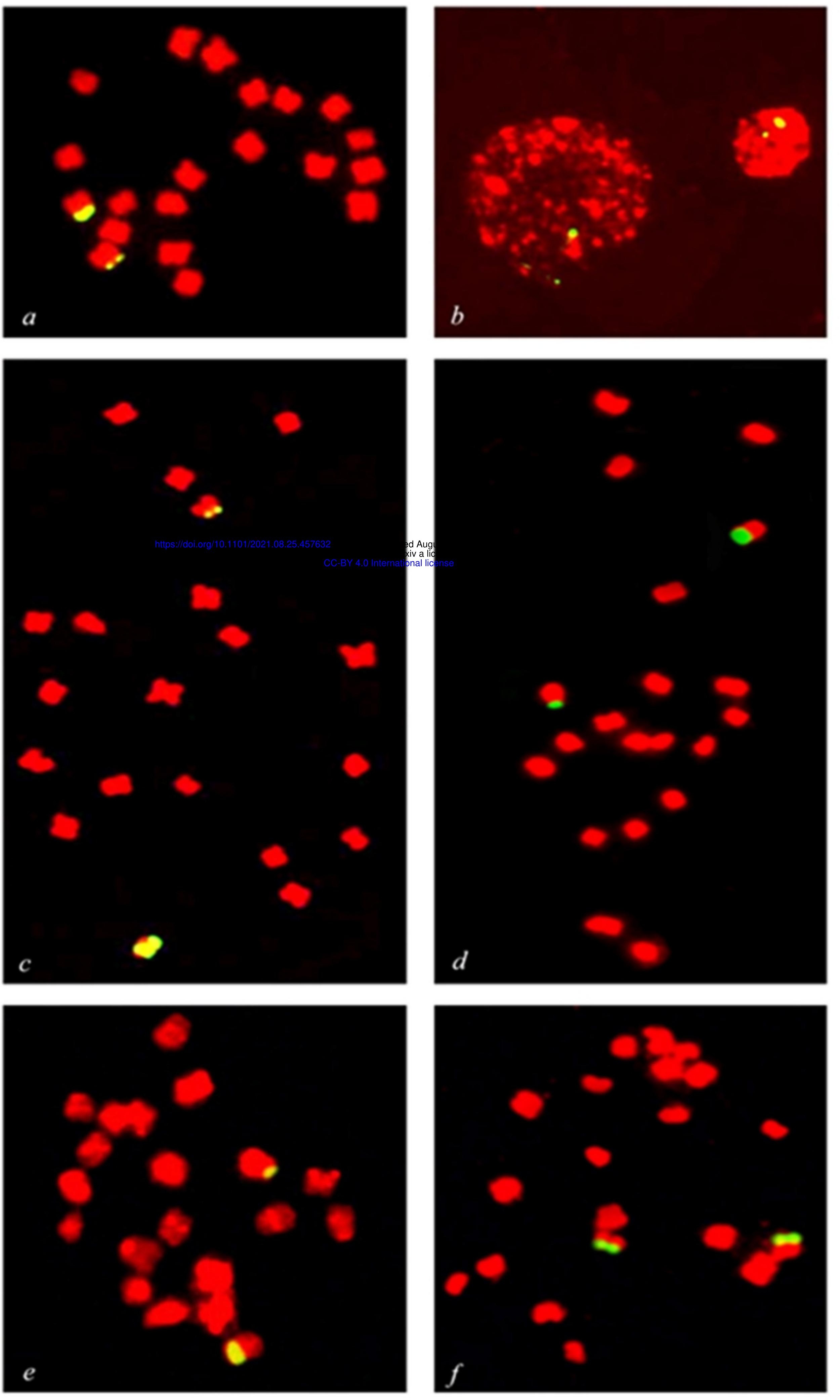

Figure 1 
Total

length

$3.12 \quad 2.75$

2.32

2.00

1.86

1.72

1.71

1.62

1.57

1.43

1.3

Arm ratio

2.253 .37

1.05

2.77

1.14

1.97

2.72

1.09

2.14

2.49

2.51
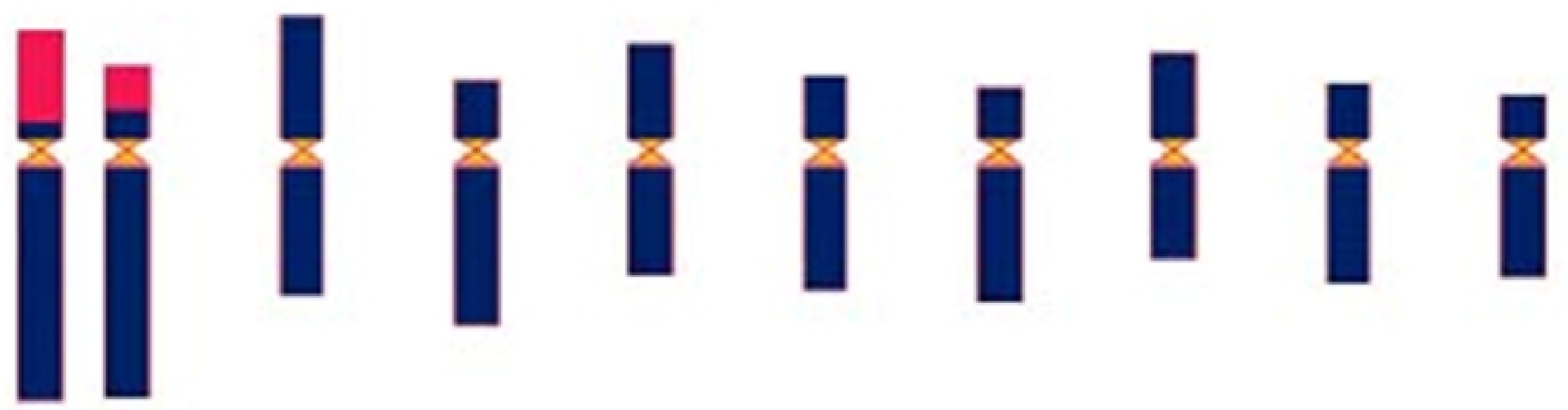

(a)

Total length

2.982 .76

$2.4 \quad 1.98$

1.8

1.74

1.72

1.53

1.58

1.4

1.31

Arm ratio $2.27 \quad 3.38$

$\begin{array}{ll}1.05 & 2.81\end{array}$

$1.12 \quad 1.9$

2.66

1.07

2.16

2.5

2.64
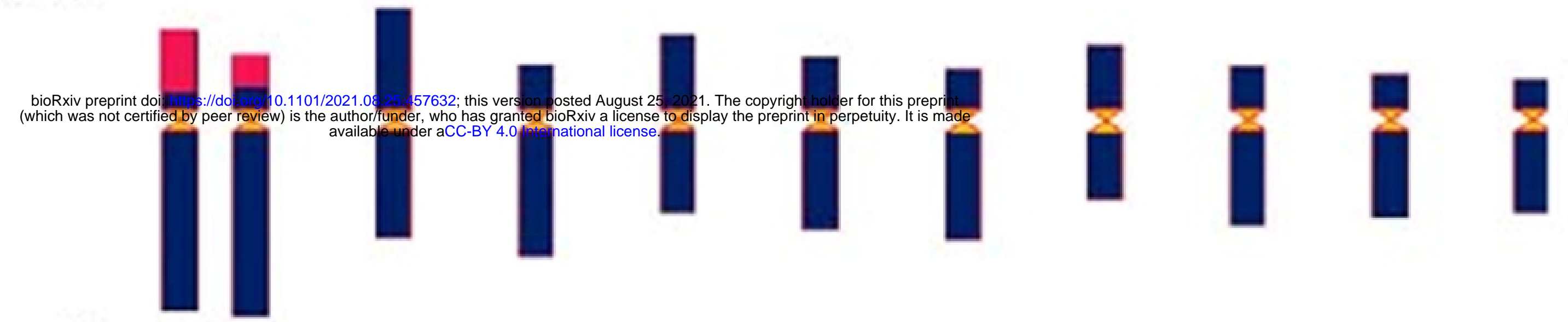

(b)

Total

length

$\begin{array}{ll}3.1 & 2.73\end{array}$

$2.22 \quad 1.95$

1.79

1.72

1.7

1.56

1.52

1.33

1.32

Arm ratio

2.263 .40

$\begin{array}{ll}1.04 & 2.82\end{array}$

1.11

1.92

2.70

1.08

$\begin{array}{ll}2.17 & 2.59\end{array}$

2.47
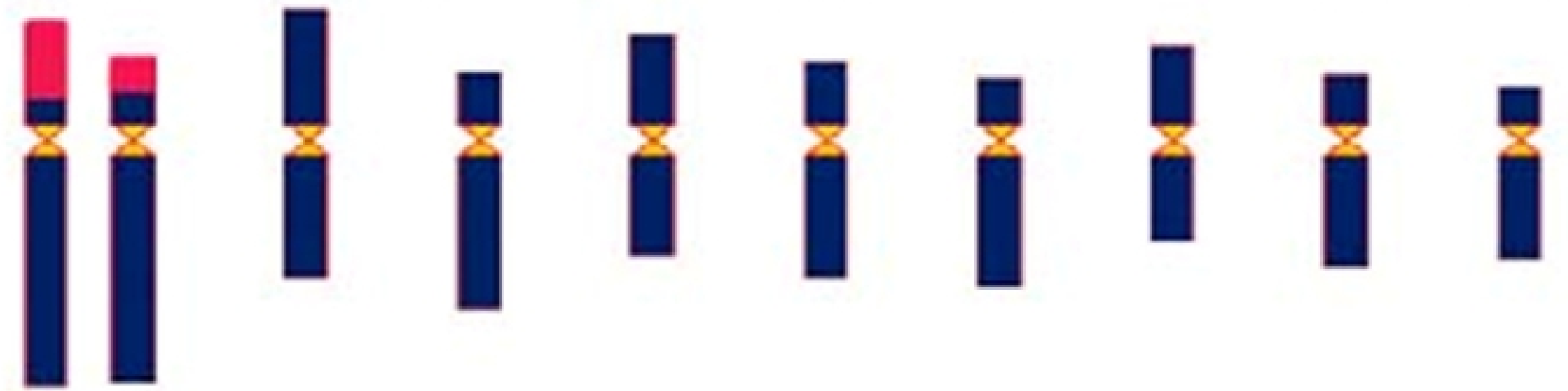

(c)

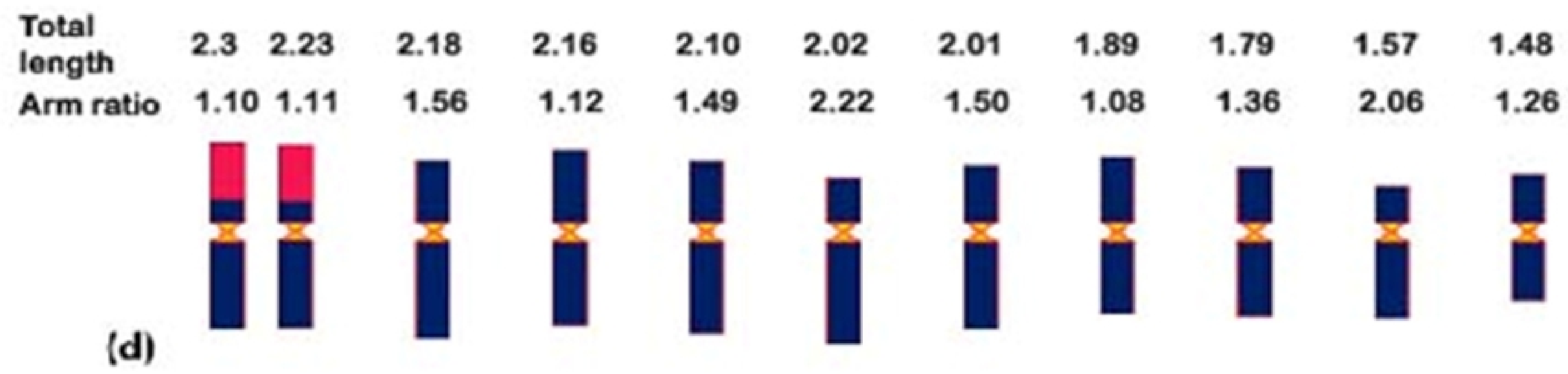

Figure 2 


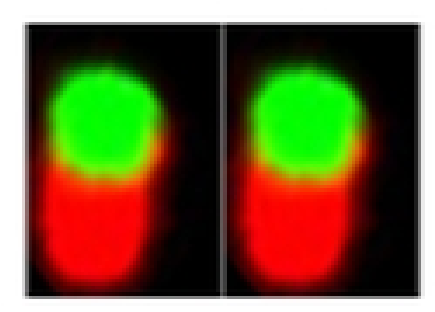

Cymbopogon species I
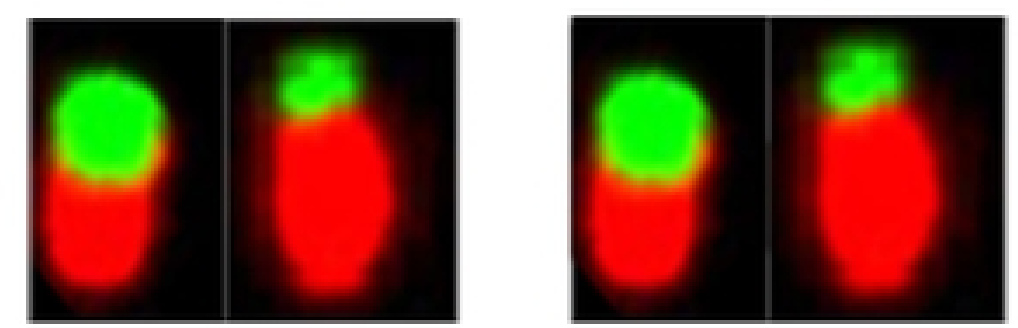

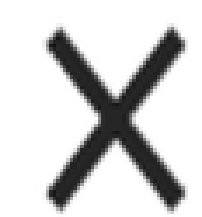

$\downarrow$

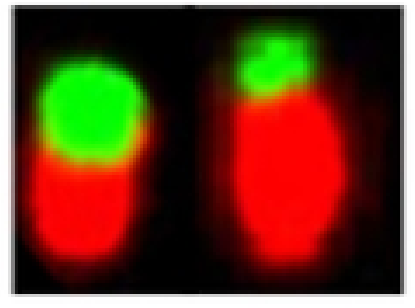

Cymbopogon species 2

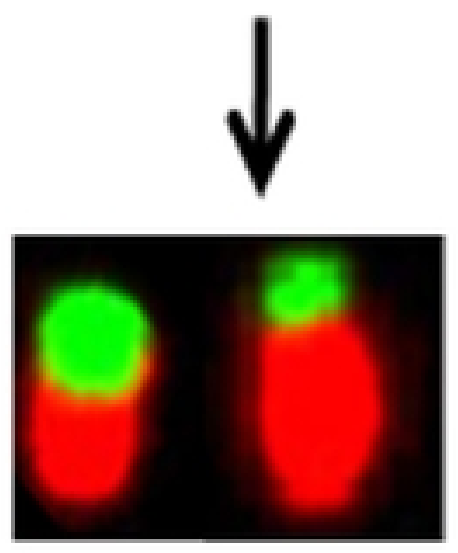

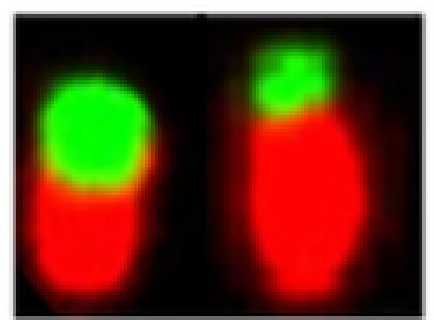

FI Generation

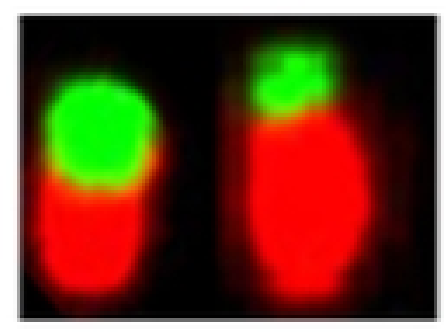

Clonal selection and vegetative

propagation

Figure 3 